Gut, 1983, 24, 73-77

\title{
Motility of neutrophils and monocytes in Crohn's disease and ulcerative colitis
}

\author{
J M RHODES* and D P JEWELL $\dagger$ \\ From the Department of Medicine, Royal Free Hospital, London
}

SUMMARY Random motility and chemotaxis of peripheral blood neutrophils and monocytes from patients with Crohn's disease and ulcerative colitis have been measured using a modified Boyden Chamber filter assay. Increased random motility and chemotaxis of monocytes were found in patients with active ulcerative colitis. Monocyte motility was normal in Crohn's disease and no abnormality of neutrophil motility or chemotaxis was found in either disease. Drug therapy with prednisolone or sulphasalazine received in vivo was found to have no effect on the motility of the washed neutrophils and monocytes in vitro. This work adds to the evidence that monocytes are activated in ulcerative colitis but does not support the hypothesis that Crohn's disease is due to an inherent defect in phagocyte motility.

Granulomas are a characteristic feature of Crohn's disease but the factors leading to their formation are unknown. In the absence of an identifiable specific antigen one possible explanation could be an underlying phagocyte defect leading to defective clearance of all foreign antigens in away analogous to chronic granulomatous disease of childhood. Although phagocytosis ${ }^{12}$ and intracellular killing ${ }^{3-5}$ by neutrophils and monocytes are generally normal or enhanced in Crohn's disease, Segal and Loewi ${ }^{6}$ found a marked diminution of neutrophil chemotaxis into skin-window chambers containing the patient's own serum. Their results could be explained not only by an intrinsic defect in neutrophil chemotaxis or motility but also by the presence of serum inhibitors or abnormalities in vascular permeability or coagulation. It is, therefore, important to know whether the neutrophils move normally in the absence of serum.

Granulomas have been shown to arise from cells of the monocyte/macrophage series. ${ }^{7}$ It is possible, therefore, that Crohn's disease could also result from a defect in monocyte motility causing delayed clearance of foreign material from the gut mucosa. There has not previously been any published study of monocyte motility in Crohn's disease.

Ulcerative colitis differs histologically from

\footnotetext{
* Present address and for correspondence: Department of Medicine, Queen Elizabeth Hospital. Edgbaston. Birmingham.

+ Present address: John Radcliffe Hospital, Headington, Oxford.

Received for publication 7 April 1982
}

Crohn's disease by having a more marked infiltrate of acute inflammatory cells and no tendency to granuloma formation. ${ }^{8}$ The severe forms of each disease do, however, cause very similar systemic effects, so ulcerative colitis provides a useful disease control for this study. Previous work has suggested that peripheral blood monocytes tend to be hyperactive in ulcerative colitis, ${ }^{59}$ so it was also of interest to determine whether motility of monocytes is enhanced in patients with this disease.

\section{Methods}

Twenty patients with Crohn's disease and 20 with ulcerative colitis were studied. Disease activity was evenly distributed between inactive, mild, moderate, and severe, assessed according to recognised criteria. ${ }^{10} 11$ Twenty patients were receiving prednisolone or sulphasalazine at the time of the study ( 10 with Crohn's disease and 10 with ulcerative colitis). Patients receiving other forms of drug therapy were not studied. Twenty healthy subjects approximately matched for age and sex were also studied.

\section{CELL ISOLATION}

Venous blood $(20 \mathrm{ml})$ was taken on the morning of the test and heparin (5 units $/ \mathrm{ml}$ ) added. Erythrocytes were sedimented with Dextran 110 in $0.9 \%$ sodium chloride $(150 \mathrm{mmol} / \mathrm{l}$ (mequiv/l); Fisons) for 30 minutes at $37^{\circ} \mathrm{C}$ and the supernatant was then centrifuged on a Ficoll-Hypaque (Histopaque; 
Sigma) density gradient ${ }^{12}$ at $400 \mathrm{~g}$ for 30 minutes at $15^{\circ} \mathrm{C}$. Neutrophils were obtained from the cell pellet (purity $>95 \%$ ) after incubation in $0.87 \%$ buffered ammonium chloride for five minutes to lyse residual erythrocytes. Mononuclear cells were obtained from the interface and centrifuged at $150 \mathrm{~g}$ to reduce platelet contamination. The resulting cell population contained $>60 \%$ monocytes by peroxidase staining. This relatively high monocyte proportion probably resulted from glass adherence during the washing process. The remaining cells were lymphocytes with less than $1 \%$ neutrophil contamination. The cells were washed twice, resuspended in Gey's medium ${ }^{13}$ containing pure human serum albumin $(1 \mathrm{mg} / \mathrm{ml}$; Behringwerke $)$ and corrected to a final concentration of $2 \times 10^{6}$ cells $/ \mathrm{ml}$.

\section{CHEMOTAXIS AND RANDOM MOTILITY ASSAYS}

The modified Boyden chamber assay ${ }^{14}$ described by Wilkinson ${ }^{13}$ was used; $3 \mu \mathrm{m}$ pore diameter filters (Millipore) were used for neutrophil chemotaxis and $8 \mu \mathrm{m}$ pore diameter for monocyte chemotaxis. Chemotaxis was directed towards casein $(4 \mathrm{mg} / \mathrm{ml}$; Sigma) dissolved in Gey's medium. Random motility was assayed in the presence of purified human serum albumin (1 $\mathrm{mg} / \mathrm{ml}$; Behringwerke) dissolved in Gey's medium. Neutrophil chemotaxis and random motility were allowed to proceed for 40 and 75 minutes respectively, monocyte chemotaxis and random motility for two hours. The chambers were placed in a humidified incubator contining air $+\mathrm{CO}_{2} 95: 5, \mathrm{v} / \mathrm{v}$ at $37^{\circ} \mathrm{C}$. Each filter was then fixed in absolute alcohol, mounted, and stained with haematoxylin. The distance in microns moved by the leading cell front was measured in five randomly selected high power fields with the micrometer focusing adjustment of a Leitz SM microscope. The leading cell front was taken to be the lowest plane through the filter in which two or more cells were in focus. Each assay was run in triplicate so that each result represents the mean of 15 observations. The 15 observations obtained from each sample showed acceptable reproducibility (coefficients of variation: neutrophil chemotaxis $10 \%$, neutrophil random motility $19 \%$, monocyte chemotaxis $8 \%$, monocyte random motility $18 \%$ ).

\section{STATISTICAL METHODS}

Results in the three groups were compared with one-way analysis of variance. If significance was demonstrated Student's $t$ test was used.

\section{Results}

There was no significant difference in neutrophil chemotaxis between healthy subjects $(76 \cdot 0 \pm 10 \cdot 8$ $\mu \mathrm{m})$ and patients with Crohn's disease (74.1 $\pm 16 \cdot 4$ $\mu \mathrm{m})$ or ulcerative colitis $(69.1 \pm 18.4 \mu \mathrm{m})(\mathrm{F}=1.05$ by analysis of variance) (Fig. 1). There was also no signicant difference in neutrophil random motility between the groups: healthy subjects $34 \cdot 6 \pm 8 \cdot 3 \mu \mathrm{m}$, Crohn's disease $35 \cdot 3 \pm 7 \cdot 2 \mu \mathrm{m}$, and ulcerative colitis $38.5 \pm 10.7 \mu \mathrm{m}(\mathrm{F}=1 \cdot 10$ by analysis of variance $)$ (Fig. 2).

Monocyte chemotaxis was significantly raised in the patients with ulcerative colitis $(125.9 \pm 12.3 \mu \mathrm{m})$, but not in patients with Crohn's disease (120.6 $\pm 14 \cdot 3$ $\mu \mathrm{m})$ compared with healthy subjects $(114.7 \pm 13.7$ $\mu \mathrm{m})(\mathrm{p}<0.05$ by analysis of variance, ulcerative colitis $v s$ healthy subjects $\mathrm{p}<0 \cdot 01$ by Student's $t$ test) (Fig. 3). Random motility of monocytes from ulcerative colitis patients $(41.9 \pm 10.1 \mu \mathrm{m})$ was enhanced compared with those from Crohn's disease patients $(32 \cdot 8 \pm 7.2 \mu \mathrm{m})$ and healthy subjects $(34.9 \pm 12.1 \mu \mathrm{m})$ (Fig. 4) ( $\mathrm{p}<0.05$ by analysis of variance; ulcerative colitis vs Crohn's disease $\mathrm{p}<0.005$ by Student's $t$ test; ulcerative colitis $v s$ healthy subjects $p<0 \cdot 1,>0.05$ by Student's $t$ test).

The enhanced monocyte chemotaxis found in ulcerative colitis correlated with increasing disease activity (Fig. 5) ( $t$ for linear trend, 3.202; $\mathrm{p}<0.005$ ). There was no significant difference between the chemotaxis of monocytes from patients with total colitis $(127.1 \pm 11.7 \mu \mathrm{m})$ and monocytes from patients who only had radiologically evident disease distal to the splenic flexure $(124 \cdot 9 \pm 13 \cdot 2 \mu \mathrm{m})$. To ensure that differences in drug therapy were not affecting the results obtained, monocyte chemotaxis in both Crohn's disease and ulcerative colitis patients was compared between the different treatment groups. There was no significant

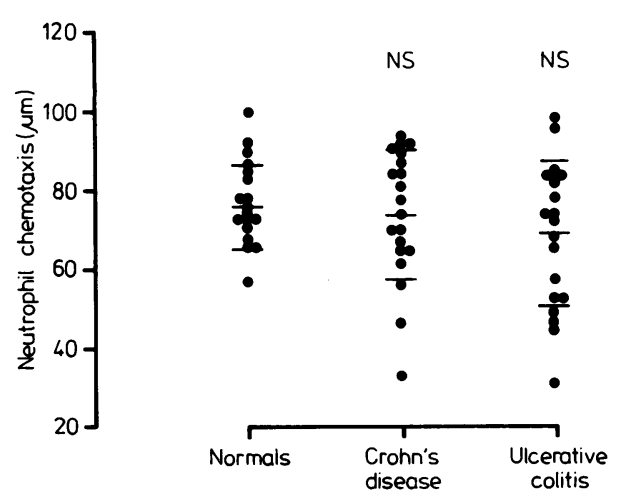

Fig. 1 Casein-stimulated chemotaxis (microns moved by leading cell front in 40 minutes) of neutrophils from normal subjects and from patients with Crohn's disease or ulcerative colitis (mean $\pm S D$ ). 


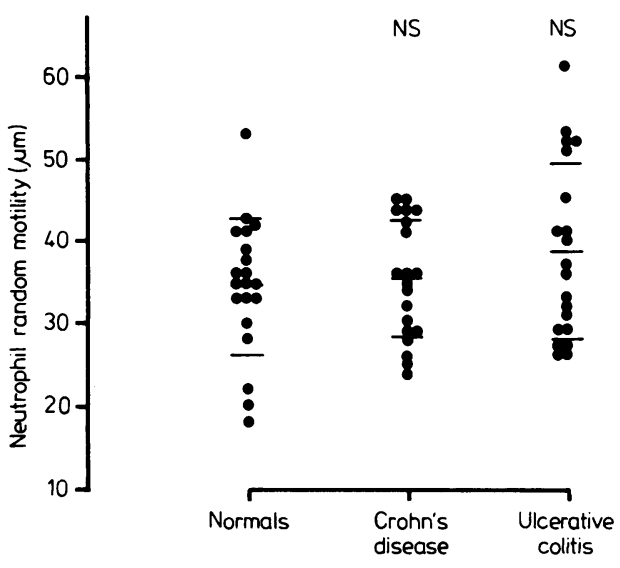

Fig. 2 Random motility (after 75 minutes) of neutrophils from normal subjects and from patients with Crohn's disease or ulcerative colitis (mean $\pm S D$ ).

difference between the results obtained from patients receiving no therapy $(120.9 \pm 13.4 \mu \mathrm{m})$, prednisolone in a mean dosage of $23.8 \pm 11.1 \mathrm{mg} /$ day $(126 \cdot 7 \pm 13 \cdot 1 \mu \mathrm{m})$, or sulphasalazine $2 \mathrm{~g} /$ day $(124.4 \pm 13.1 \mu \mathrm{m})(\mathrm{F}=0.76, \mathrm{NS})$. Drug therapy was also found to have had no significant effect on neutrophil chemotaxis: patients receiving no therapy $(74.8 \pm 12.8 \mu \mathrm{m})$, prednisolone in a mean dosage of $23.8 \pm 11.1 \mathrm{mg} /$ day $(66.5 \pm 22.7 \mu \mathrm{m})$, sulphasalazine $2 \mathrm{~g}$ /day $(73.6 \pm 21.8 \mu \mathrm{m}),(\mathrm{F}=0.81$, NS).

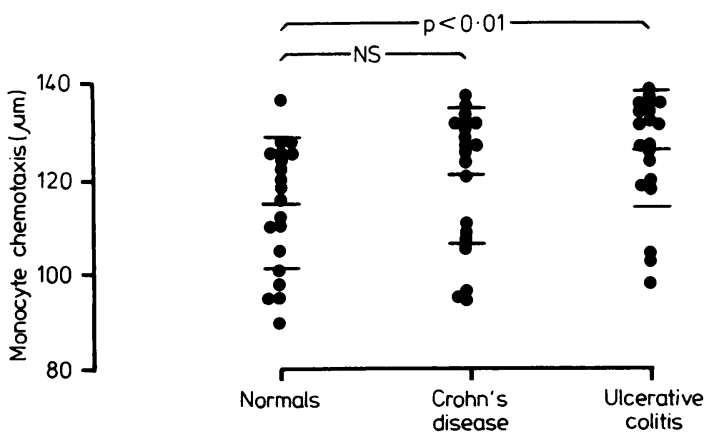

Fig. 3 Casein-stimulated chemotaxis (microns moved by leading cell front in 120 minutes) of monocytes from normal subjects and from patients with Crohn's disease or ulcerative colitis (mean $\pm S D$ ).
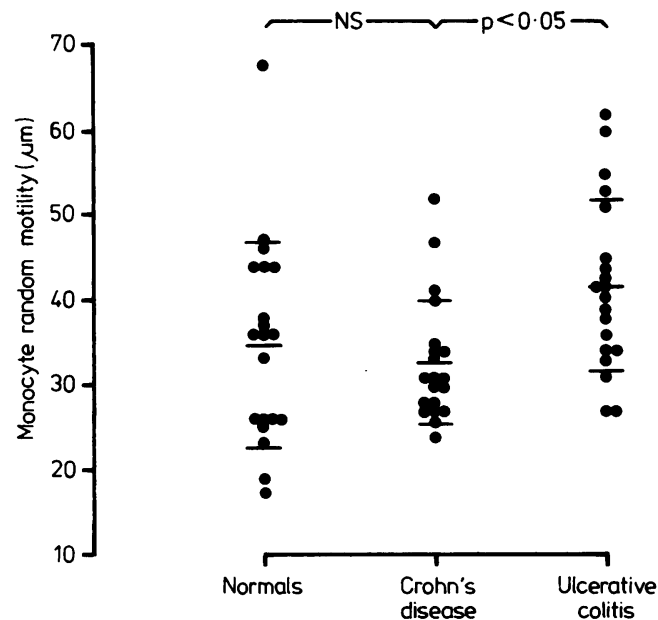

Fig. 4 Random motility (after 120 minutes) of monocytes from normal subjects and from patients with Crohn's disease or ulcerative colitis (mean $\pm S D$ ).

\section{Discussion}

These results show that isolated neutrophils and monocytes from patients with Crohn's disease exhibit normal random motility and chemotaxis. Since this work was carried out, O'Morain et al have also reported normal neutrophil motility in Crohn's disease using a Boyden chamber filter assay, ${ }^{15}$ as have D'Amelio and colleagues using an agarose plate assay. ${ }^{16}$ These findings make untenable the hypothesis that Crohn's disease results from an

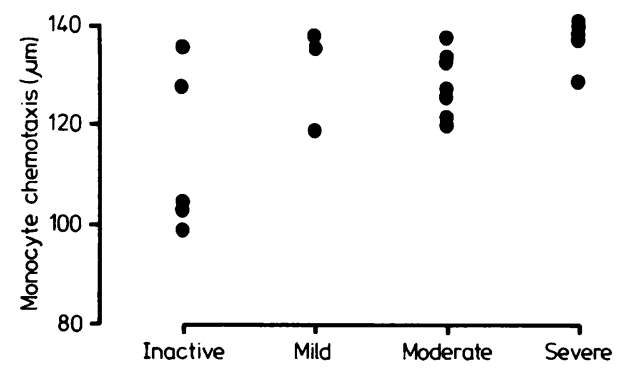

Fig. 5 Relationship between monocyte chemotaxis and clinically assessed disease activity in patients with ulcerative colitis. 
intrinsic defect in phagocyte motility. The depression of neutrophil chemotaxis into skin windows demonstrated in Crohn's disease by Segal and colleagues ${ }^{615}$ may, therefore, result from the presence of a serum inhibitor or an abnormality in vascular permeability rather than a defect in the neutrophils themselves. In their recent study they did not find serum inhibitory activity in Crohn's disease. ${ }^{15}$ There is, however, evidence from work carried out by ourselves ${ }^{17}$ and D'Amelio ${ }^{16}$ that serum inhibitors of chemotaxis may occur nonspecifically in patients with active Crohn's disease.

Binder and Riis ${ }^{18}$ and Hermanowicz and Nawarska ${ }^{19}$ found that isolated neutrophils from patients with ulcerative colitis showed enhanced random motility, but reduced chemotaxis. In the present study a similar trend has been found, but this was not statistically significant. In both studies there is a very considerable overlap between the values obtained both for neutrophil random motility and chemotaxis in ulcerative colitis and normal controls. It therefore seems unlikely that there is any important underlying abnormality of neutrophil motility in ulcerative colitis.

Monocyte chemotaxis is shown to be significantly enhanced in ulcerative colitis, but only by a small amount $(<10 \%)$. The fact that random motility of the monocytes is also enhanced suggests that this apparent increase in chemotaxis is probably due to increased speed of cell movement (chemokinesis) rather than altered directional motility. The finding that increased monocyte chemotaxis correlates with increased activity of the ulcerative colitis suggests that it is probably secondary to the disease state. Previous work has shown that monocyte phagocytosis $^{5}$ and monocyte lysosomal enzyme concentrations ${ }^{9}$ are also enhanced in active ulcerative colitis, so that the increase in monocyte motility may be a further indication that monocyte activation occurs during attacks of ulcerative colitis. It may well be that such activation of cells of the monocyte/ macrophage series with subsequent lysosomal enzyme release is responsible for some of the mucosal damage in ulcerative colitis.

There is also evidence of increased monocyte/macrophage activation ${ }^{59}$ and turnover ${ }^{20}$ in Crohn's disease. This study has failed to show a corresponding enhancement of monocyte motility in Crohn's disease, although casein-directed monocyte chemotaxis was slightly, albeit insignificantly, greater than that of control monocytes.

It is interesting that therapy with either prednisolone or sulphasalazine had no effect on the chemotaxis of monocytes and neutrophils in vitro. Two other studies have also shown that prednisolone therapy fails to affect neutrophil chemotaxis. ${ }^{1621}$ All these studies have, however, been performed with leucocytes that have been washed and then incubated in the absence of the patient's serum. Both prednisolone $e^{22} 23$ and sulphasalazine ${ }^{23}$ inhibit chemotaxis when added to leucocytes in vitro so a therapeutic effect on chemotaxis in vivo cannot be completely excluded, particularly if these drugs are present in the colon in high concentrations.

JMR was in receipt of a Stanley Thomas Johnson Memorial Fellowship. The work was generously supported by the British Digestive Foundation.

\section{References}

1 Ward M, Eastwood MA. The nitroblue tetrazolium test in Crohn's disease and ulcerative colitis. Digestion 1976; 14: 179-83.

2 Krause U, Michaelsson G, Juhlin L. Skin reactivity and phagocytic function of neutrophil leucocytes in Crohn's disease and ulcerative colitis. Scand $J$ Gastroenterol 1978; 13: 71-5.

3 Ament ME. Intestinal granulomatosis in chronic granulomatous disease and Crohn's disease. $N$ Engl J Med 1974; 290: 228.

4 Renz M, Ward M, Eastwood MA, Harkness KA. Neutrophil function and myeloperoxidase activity in inflammatory bowel disease. Lancet 1976; 2: 584.

5 Mee AS, Szawatkowski M, Jewell DP. Monocytes in inflammatory bowel disease: phagocytosis and intracellular killing. J Clin Pathol 1980; 33: 921-5.

6 Segal AW, Loewi E. Neutrophil dysfunction in Crohn's disease. Lancet 1976; 2: 219-21.

7 Spector WG, Lykke WJ. The cellular evolution of inflammatory granulomata. J Pathol Bacteriol 1966; 92: 163-77.

8 Morson BC, Dawson IMP. Gastrointestinal pathology 1st ed. Oxford: Blackwell, 1972: 458-84.

9 Mee AS, Jewell DP. Monocytes in inflammatory bowel disease: monocyte and serum lysosomal enzyme activity. Clin Sci 1980; 58: 295-300.

10 Truelove SC, Witts LJ. Cortisone in ulcerative colitis: final report on a therapeutic trial. $\mathrm{Br} \operatorname{Med} J$ 1955; 2: 1041-8.

11 DeDombal FT, Burton IL, Clamp SE, Goligher JC. Short-term course and prognosis of Crohn's disease. Gut 1974; 15: 435-43.

12 Boyum A. Isolation of leucocytes from human blood. Scand J Clin Lab Invest 1968; 21: suppl 97, 31-50.

13 Wilkinson PC. Chemotaxis and inflammation. 1st ed. Edinburgh: Churchill Livingstone, 1974; 118: 170-2.

14 Boyden SV. The chemotactic effect of mixtures of antibody and antigen on polymorphonuclear leucocytes. J Exp Med 1962; 115: 453-66. 
15 O'Moráin C, Segal AW, Walker D, Levi AJ. Abnormalities of neutrophil function do not cause the migration defect in Crohn's disease. Gut 1981; 22: 817-22.

16 D'Amelio R, Rossi P, LeMoli S, Ricci R, Montano S, Pallone $\mathrm{F}$. In vitro studies on cellular and humoral chemotaxis in Crohn's disease using the under agarose gel technique. Gut 1981; 22: 566-70.

17 Rhodes JM, Potter BJ, Brown DJC, Jewell DP. Serum inhibitors of leucocyte chemotaxis in Crohn's disease and ulcerative colitis. Gastroenterology 1982; 82: 132734.

18 Binder V, Riis P. The leucocyte chemotactic function in patients with ulcerative colitis. Scand J Gastroenterol 1977; 12: 141-4.
19 Hermanowicz A, Nawarska Z. Chemotaxis and random migration of polymorphonuclear leukocytes in ulcerative colitis examined by the agarose method. Scand J Gastroenterol 1981; 16: 961-6.

20 Meuret G, Bitzi A, Hammer B. Macrophage turnover in Crohn's disease and ulcerative colitis. Gastroenterology 1978; 74: 501-3.

21 Clark RAF, Gallin JI, Fauci A. Effects of in vivo prednisolone on in vitro eosinophil and neutrophil adherence and chemotaxis. Blood 1979; 53: 633-41.

22 Ward PA. The chemosuppression of chemotaxis. J Exp Med 1966; 124: 209-25.

23 Rhodes JM, Jewell DP. Inhibition of leucocyte motility by drugs used in inflammatory bowel disease. Gut 1981; 22: 642-7. 